\title{
MERCADOS EMERGENTES E AS ESTRATÉGIAS DE INOVAÇÃO NO BRASIL
}

Caio Flavio Stettiner ${ }^{1}$

Edinicio Oliveira Lima

Samuel Ferreira Junior ${ }^{2}$

Jomar Luiz Bellini ${ }^{3}$

${ }^{1}$ Doutorando / PPAGA UNIFACCAMP / Unifaccamp

${ }^{2}$ UNIFACCAMP - CENTRO UNIVERSITÁRIO CAMPO LIMPO PAULISTA

${ }^{3}$ UNIFACCAMP / Centro Universitário Campo Limpo Paulista - UNIFACCAMP 


\title{
MERCADOS EMERGENTES E AS ESTRATÉGIAS DE INOVAÇÃO NO BRASIL
}

\begin{abstract}
Resumo: Este estudo trata do levantamento das características do fenômeno da inovação verificada nos mercados de países emergentes, que resultaram em uma tipificação peculiar que vem sendo difundida na literatura corrente. A formação de significados para a inovação no contexto desses mercados, que podem ser representados por aqueles países que integram os chamados BRICS (Brasil, Rússia, Índia, China, África do Sul), envolve uma triagem preliminar dos aspectos importantes que marcam sua ocorrência nesses limites territoriais. Com esta percepção, o tema é tratado de forma a permitir identificar particularidades nas categorias teóricas de inovações baseadas em tecnologias menos complexas, próprias dos mercados emergentes, em contraposição àquele modelo de inovação baseado em alta tecnologia e orientado por Pesquisa \& Desenvolvimento $(P \& D)$, adotado nos países centrais. Nessa perspectiva o estudo tem por objetivo montar um quadro de possíveis convergências ou dissonâncias observadas com a projeção de tais particularidades nas inovações ocorridas no Brasil, procurando jogar mais luz sobre esses novos caminhos para que se possa refletir sobre a inovação no País. Metodologicamente, o estudo vale-se de um levantamento bibliográfico, procurando subsídios teóricos e dados empíricos em base secundária para descrever e discutir aspectos do fenômeno da inovação em mercados emergentes, com destaque especial para o caso brasileiro. Em vista disso, o referencial teórico apresenta breves seções contemplando: a caracterização básica dos mercados emergentes; os tipos de inovação presentes nesses mercados; $e$ as características que marcam a inovação no Brasil. Ao traçar algumas considerações críticas sobre a inovação no contexto nacional o estudo aponta para a defasagem do Brasil no ranque mundial, com um desempenho incompatível com o porte de sua economia. Em que pese as dificuldades observadas, surgem, graças a iniciativas arrojadas nem sempre de caráter institucional, ideias, empreendimentos novos, tecnologias de ponta, mostrando uma face potencial de um Brasil inovador. Apresenta, por último, considerações sobre a inovação no mercado brasileiro e aponta objetos merecedores de investigação futura.
\end{abstract}

Palavras Chave: Inovação. Estratégia.Mercados Emergentes.

Abstract:This study deals with the survey of the characteristics of the phenomenon of innovation verified in emerging markets countries, which resulted in a peculiar typification that has been widespread in the current literature. The formation of meanings for innovation in the context of these markets, which can be represented by those countries that make up the socalled BRICS (Brazil, Russia, India, China, South Africa), involves a preliminary screening of the important aspects that mark their occurrence in these markets. Territorial boundaries. With this perception, the theme is treated in order to identify particularities in the theoretical categories of innovations based on less complex technologies, typical of emerging markets, as opposed to that model of high technology-based and R\&D-driven innovation adopted in the countries central. From this perspective, the study aims to assemble a picture of possible convergences or dissonances observed with the projection of such particularities in the 
innovations that occurred in Brazil, seeking to shed more light on these new paths so that we can reflect on the innovation in the country. This study uses a bibliographic survey, looking for theoretical support and empirical data on a secondary basis to describe and discuss aspects of the phenomenon of innovation in emerging markets, with special emphasis on the Brazilian case. In view of this, the theoretical framework presents brief sections covering the basic characterization of emerging markets; the types of innovation present in these markets; and the characteristics that mark innovation in Brazil. By outlining some critical considerations about innovation in the national context, the study points to Brazil's lag in the world rank, with a performance incompatible with the size of its economy. In spite of the difficulties observed, thanks to bold initiatives that are not always institutional in nature, ideas, new ventures, cuttingedge technologies emerge, showing a potential face of an innovative Brazil. Finally, it presents considerations on innovation in the Brazilian market and points out objects worthy of further investigation.

Keywords: Innovation. Emerging Markets. Strategy.

\section{INTRODUÇÃO}

O reconhecimento da inovação como fator determinante para o progresso econômico de países e empresas já era realçado por Schumpeter (1997). Nessa linha, Prahalad e Hamel (2005), entendem que a inquietação decorrente dos desdobramentos do fenômeno da globalização continua provocando a desintegração de mercados e impondo às organizações condições competitivas desafiadoras. O enfrentamento dessas condições vem ficando cada vez mais dependente da agilidade e da capacidade inovadora das organizações. Christensen (2012) também afirma que as empresas e os mercados defrontam-se com o desafio da inovação, cuja solução assegura um crescimento em base sustentável.

A revista Economist explorando a coletânea de Adrian Wooldridge The Great Disruption, analisou a ruptura e influências que vem deixando o ambiente de negócios turbulento, percebendo que a interrupção dos velhos paradigmas vem ocorrendo por força de vários fatores: a robotização migrando das plataformas de fábricas para a industrialização dos serviços; a velocidade da propagação da internet; novos modelos de gestão forçando empresas a revisarem suas estratégias; e a imposição aos mercados emergentes da adoção de novos processos produtivos e de inovação. Essas condições vêm mobilizando empresas e provocando mudanças e agitação social, forçando o fenômeno da inovação nos países emergentes a ponto de causar perturbação nos países centrais (WOOLDRIDGE, 2017).

De fato, o salto de países emergentes como Índia e China, segundo essa edição da Revista inglesa, não pode mais ser explicado apenas pelo custo de mão de obra, mas também, pela força da inovação. Empresas de países emergentes demonstraram grande força competitiva, inclusive no contexto global. O processo de expansão dos emergentes atuais valese da inovação, tal como ocorreu há quatro décadas com a inovação no modo de produção ocorrida no Japão, observa a Revista.

Com menos destaque entre os chamados BRICS, o Brasil também foi mencionado na reportagem, que relacionou problemas e restrições dos países em desenvolvimento com a necessidade das empresas se desdobrarem em eficiência, restando da combinação desses fatores um ambiente favorável à inovação. 
Nesse encadeamento, a Economist mostra com dados convincentes que o mercado emergente vem experimentando uma rápida expansão e o Brasil, embora ainda tímido quando comparado aos outros países, teve suas 20 maiores empresas aumentando significativamente seus ativos no exterior na última década.

Antecipando esses pontos de vista, Reinert e Reinert (2003) também deixaram o entendimento que o desenvolvimento no quadro atual é fortemente dependente da inovação gerada pelo conhecimento e essa condição inclui os países emergentes, explicando o esforço de aprendizagem que vem sendo empreendido nessas nações.

Entende-se do estudo desses autores, que em um mundo que o conhecimento constitui insumo de primeira grandeza no processo produtivo, a inovação resultante torna-se componente fundamental para o desempenho competitivo das organizações e fortalecimento econômico de nações.

É recorrente na literatura a ideia de que o domínio da tecnologia e o investimento em pesquisa vem sendo os principais mecanismos utilizados para a inovação nos países desenvolvidos, assegurando-lhes o predomínio político e econômico. Enquanto isso, as empresas atuantes nos mercados emergentes padecem da privação de recursos financeiros, de recursos materiais e de pessoal qualificado, o que regularmente vem sendo apontado como condições que dificultam a estruturação de uma base tecnológica e a geração de inovação (FIGUEIREDO, 2011).

Em que pese a incidência de casos pontuais de prósperas inovações, o que fica mais evidente na conjuntura nacional é a ocorrência de pouco investimento no âmbito dos negócios e na esfera institucional e de pequena capacidade tecnológica, o que gera severas restrições ao processo de inovação no País. Isso explica, em parte, porque a posição do Brasil no ranque mundial de inovação mostra-se incompatível com o tamanho da sua economia (SARKAR, 2008).

Essas referências já permitiriam levantar várias questões suscetíveis de investigação. Mas o presente estudo limita-se a examinar a ocorrência de tipos de inovação nos mercados emergentes para suscitar a reflexão sobre a conformidade do Brasil, enquanto emergente, com essa tipologia de inovação. Seria de se pensar, então, sobre as condições do País para enfrentar o desafio da inovação, restando indagar: Quais são as estratégias de inovação típicas de mercado emergentes encontradas no Brasil?

Com a perspectiva de jogar mais luz sobre os novos caminhos adotados nos mercados emergentes e para que se possa refletir sobre a indagação que questiona a inovação no Brasil, o estudo tem por objetivo:

Montar um quadro de possíveis convergências ou dissonâncias observadas entre inovações no Brasil e os modelos adotados nos mercados emergentes.

Especificamente, o objetivo proposto terá os seguintes desdobramentos: (i) descrever as estratégias de inovação em mercados emergentes; (ii) descrever as estratégias de inovação observadas no Brasil; (iii) elaborar relação entre inovação em mercado emergentes e inovação no Brasil.

\section{$2 \quad$ METODOLOGIA}

O estudo valeu da abordagem qualitativa de pesquisa, a qual fundamenta-se num conjunto de práticas materiais e interpretativas que possibilitam compreender a realidade, 
possui um caráter interpretativo e uma abordagem natural diante do mundo ao estudar e interpretar os fenômenos dentro dos contextos que os sujeitos imputam (FLICK, 2009).

Optou-se por esta abordagem por ser adequada para explicar os fenômenos sociais ou grupais, históricos, vivenciais e realísticos por meio da interação da análise teórica, da pesquisa empírica. (BULMER 1977; FLICK, 2009).

Nessa linha, foram realizados levantamento bibliográfico e documental, procurando subsídios teóricos e dados empíricos em base secundária para descrever e analisar aspectos do fenômeno da inovação em mercados emergentes, com destaque especial para o estudo do caso brasileiro em base secundária, onde se procurou levantar estratégias de inovação típica de mercados emergentes encontradas no Brasil.

O estudo de caso envolve e explora dados empíricos de um determinado fenômeno dentro de um contexto particular, utilizando múltiplas fontes de evidências, e contribuindo para o conhecimento do pesquisador sobre os fenômenos individuais, grupais, organizacionais, sociais, políticos (EISENHARDT, 1989; CRESWELL, 2010; YIN, 2010).

A coleta de dados pela técnica da pesquisa bibliográfica, realizada em livros, artigos em periódicos científicos, anais de congresso e site especializados no tema, tem como objetivo compreender e analisar as contribuições científicas sobre determinado assunto, tema ou problema (FLICK, 2009; GIL, 2010; KÖCHE, 2010).

\section{ESTRATÉGIA E INOVAÇÃO}

O tema inovação vem sendo exaltado nos âmbitos empresariais e nos mercados nacionais. Tratado como fator primordial para o estabelecimento de vantagens competitivas duradouras e crescimento defensável para empresas e nações, a inovação vem sendo definida com certa imprecisão o que impõe restrições na sua gestão tanto na esfera empresarial quanto pública, Drucker (2005).

O autor, continua lembrando que a inovação é o mecanismo que o empreendedor utiliza para explorar as oportunidades originadas na mudança e por isso ele precisa da direção estratégica e da força do conhecimento para executar os fundamentos da inovação.

Diversas abordagens teóricas explicam o pensamento e a formulação da direção estratégica no mundo organizacional. Pode passar pelo formalismo prescritivo liderado por Ansoff (1965), numa ponta, ou pelos saltos de configuração de Mintzberg (2002), no outro extremo. Pode-se inferir da análise desse último autor que a formação da estratégia assume um caráter particularizado, que vai depender, dentre outros aspectos, do fundamento competitivo sob o qual a estratégia estará ancorada.

Como foi mencionado, a inovação vem figurando como importante fundamento estratégico para uma diferenciação em base sustentável. De acordo com Porter (1989) existem três estratégias genéricas possíveis: liderança em custo, diferenciação e enfoque. A tendência de fracionamento cada vez maior do mercado vem requerendo das empresas uma abordagem estratégica cada vez mais diferenciada, o que lhes impõe de modo irreversível a necessidade de inovar.

Dentre tantas abordagens possíveis, a formação da estratégia na concepção RBV (Visão Baseada em Recursos) vem mostrando-se adequada para guiar a organização rumo à inovação. Consiste numa abordagem centrada na utilização de recursos imateriais para estabelecer condições competitivas sustentáveis, Hitt, Ireland e Hoskisson (2008). Os autores continuam 
lembrando que o compartilhamento sistemático do recurso intangível, como o conhecimento, assegura a inovação. A perspectiva da RBV é a formação de competências, que derivam de habilidades e conhecimentos de difícil imitação e por isso podem estabelecer vantagem competitiva duradoura.

Para inovar, é necessário repensar padrões e conceitos, romper barreiras e agregar valor, visando a sua aplicabilidade para as pessoas e retornos no campo econômico, social ou financeiro, segundo Grizendi (2011), Bessant e Tidd (2009).

Para Schumpeter, em seu livro "A Teoria do Desenvolvimento Econômico" reeditado em 1997, a inovação está presente em todas as sociedades, confunde-se quem pensa que ela está inserida somente no contexto de produção de novas ideias, ela não se restringe ao novo, mas também a adaptação, aperfeiçoamento de algo já existente, tanto em termos de processos, quanto de produtos, quando são recriados para acompanhar a mudança.

Inovação é a prática de ideias associadas a avanços radicais ou melhorias graduais. Pensando nisso, Tidd, Bessant e Pavitt (2008) avançaram no conhecimento sobre o processo de gestão de inovação nas organizações, delineando características que requerem quatro condições básicas: (i) enfoque estratégico, (ii) mecanismos efetivos de implantação, (iii) clima organizacional favorável e (iv) vínculos externos efetivos.

Ainda para Tidd, Bessant e Pavitt (2008), uma inovação é sempre uma quebra de paradigma na organização que a introduz, é um processo de tentativas e buscas. Ao introduzirem inovações no mercado, as organizações não alteram apenas as suas posições relativas nele, mas alteram o próprio mercado. A inovação faz com que se criem expectativas de obter vantagens competitivas em relação às demais organizações.

Van De Ven (1986) entende que o processo de inovação como sendo o desenvolvimento e a implantação de novas ideias por pessoas que interagem entre si em um contexto institucional. Essa ideia também é compartilhada por Quinn (1996), acrescentando que o poder econômico e de produção de uma empresa está mais em suas capacidades intelectuais e de serviços do que em suas instalações, terras etc. Ele sugere que o valor da maioria dos produtos e serviços dependem, principalmente, de como os fatores intangíveis baseados no conhecimento podem ser desenvolvidos.

O Manual de Oslo, editado pela Organização para a Cooperação e o Desenvolvimento Econômico (OCDE, 2005), responsável pela definição de inovação adotada mundialmente, fez uma alteração que expandiu o conceito de inovação, abrangendo o setor de serviços e removendo a palavra "tecnológica" da definição, estabelecendo como possível a inovação em produtos, em processos, em serviços, em marketing e em sistemas organizacionais.

Segundo a Organisation for Economic Co-opperation and Developmet (OCDE, 2005), a inovação pode estar presente na firma através de quatro formas: (i) Inovação de Produto: introdução de um produto novo ou melhorado, no que se refere a suas características ou usos; (ii) Inovação de Processo: implementação de método de produção diferenciado, ou novo, ou melhorado; (iii) Inovação de Marketing: aplicação de um método de marketing novo com alterações na concepção do produto, embalagem, posicionamento no mercado, promoção ou fixação de preços; e (iv) Inovação Organizacional: introdução de novo método organizacional nas práticas gerenciais da empresa, na organização do local de trabalho ou mesmo nas relações externas e internas da firma. Nesse caso, podem ser aspectos tangíveis e intangíveis. 
As áreas fundamentais de atuação da gestão da inovação são: (i) organização (sistemas de gestão, modelo de negócio, gerenciamento de pessoas); (ii) estratégia (visão de futuro, metas e objetivos), Chandler e Daems (1994). (iii) Recursos disponíveis (materiais e intangíveis como o conhecimento) Barney e Hesterly (2008). (iv) Aprendizado realizado mediante formas de transferência de conhecimento, como relações com centros de P\&D e com universidades; apoio e incentivo a programas de capacitações, atualizações e cursos; visitas a feiras e exposições, Tidd, Bessante e Pavitt (2008). (v) Melhoria dos processos da empresa para desenvolvimento de seus produtos ou serviços, Barney e Hesterly (2008).

\section{MERCADOS EMERGENTES E TIPOS DE INOVAÇÃO}

Mercados Emergentes são caracterizados por regiões cuja população pertence a chamada base da pirâmide e é formada por pessoas de extrema pobreza, de classes menos favorecidas, de baixa renda (Guesalaga; Marshall, 2008). Nessa faixa encontram-se 4 bilhões de pessoas vivendo com menos de US\$ 9,05 por dia (Khalid et al., 2015).

Essa situação permite perceber a existência de oportunidades de negócios orientados para o atendimento dos mais pobres, desenvolvendo produtos e serviços de beneficiando esse mercado consumidor. Nesse caso, o aumento do volume da produção pode compensar as margens baixas obtidas nesse mercado. (Angot; Plé, 2015).

No Brasil, as classes sociais A e B alcançam 54 milhões de pessoas, a $\mathrm{C}$ atinge aproximadamente 96 milhões, as D e E próximo a 38 milhões (Barki; Parente, 2010). As necessidades da base da pirâmide merecem mais estudos (Rocha; Rocha, 2012), mas vê-se aí uma oportunidade de negócios que permita a diminuição das desigualdades, permitindo um maior acesso a bens e serviços (SANCHES; SCHMID, 2013).

A expressão "Base da Pirâmide" foi documentada pelo professor Krishnarao Prahalad, em seu livro "A Riqueza da Base da Pirâmide: Como erradicar a pobreza com lucro", em 2010. Ele define que 4 bilhões de pobres poderão participar de forma significativa em uma próxima etapa de prosperidade econômica no mundo. Para isso, não se deve pensar que são vítimas ou fardos, e sim pensar em consumidores criativos e com potencial valor (ANGOT; PLÉ, 2015).

Para compreender este mercado e sua classificação ficam assim estabelecidas: (i) Pobreza relativa - Quando a renda é inferior à média nacional, com acesso a serviços de educação e saúde de baixa qualidade; (ii) Pobreza moderada - As necessidades básicas são atendidas, mas outras não, como saúde e educação, uma doença ou morte na família pode levar a extrema pobreza e, por último (iii) Extrema pobreza - as necessidades básicas como moradia e alimentação não podem ser atendidas (Sachs, 2008).

Tais classificações auxiliam nos processos de inovação e no desenvolvimento de novos produtos, conhecendo ainda mais quem são os consumidores pobres e quais suas necessidades, e como atender suas demandas, não sendo uma tarefa simples (Ghesalaga; Marshall, 2008; Rocha; Rocha, 2012).

Os consumidores da base da pirâmide têm necessidades muito específicas, e nem sempre básicas, os produtos e serviços devem ser de preço muito baixo e de muita utilidade (ANGOT, PLÉ, 2015). Para se entender esse nicho de mercado as empresas deveriam estudar suas aspirações e aplicar estratégias específicas para o segmento (PRAHALAD, 2010).

Levando em conta que $40 \%$ do orçamento familiar da classe baixa no Brasil é destinada ao consumo de alimentos, pode-se prever um volume de 100 bilhões de Reais por ano na 
aquisição de alimentos, se tornando um dos setores mais significantes para a economia do país (PARENTE, 2008).

No que se refere à inovação, são encontradas desvantagens por existir poucos recursos para atividades de inovação, sendo necessário um quadro institucional complexo para suportar o processo de inovação em PMEs (Lisowska; Stanislawski, 2015). Para Woschke e Haase (2016) inovações através da tomada de decisão nas PMEs é fundamental para contribuir ao desenvolvimento de novos produtos e a conquista de novos mercados e para se manter uma cultura de inovação.

\subsection{INOVAÇÃO GRASSROOTS}

A inovação Grassroots pode ser definida como "uma rede de ativismo e de organizações que geram soluções para o desenvolvimento sustentável" (Seyfang \& Smith, 2007, p.16), com parcerias de diversas formas como cooperativas, associação de voluntários, grupos informais na comunidade e negócios sociais.

Os próprios atores passam a ensinar e treinar outras comunidades, ou seja, com a transferência de conhecimento os participantes passam a ser agentes replicadores do processo de inovação (RTS, 2015).

A comunidade local procura a solução de um problema que pode estar relacionado ao acesso a matéria-prima, ao desenvolvimento da agricultura, ao fornecimento de energia, à capacitação de mão de obra, etc. Estimulando a organização e a cooperação entre as comunidades envolvidas na avaliação, diagnóstico, estratégias, planejamento e implementação (RTS, 2015). Por meio de publicações científicas, ONGs, voluntários ou empresas privadas, o projeto pode ser replicado em outras regiões que enfrentam o mesmo problema (MONTEIRO; ROSSETO, 2018).

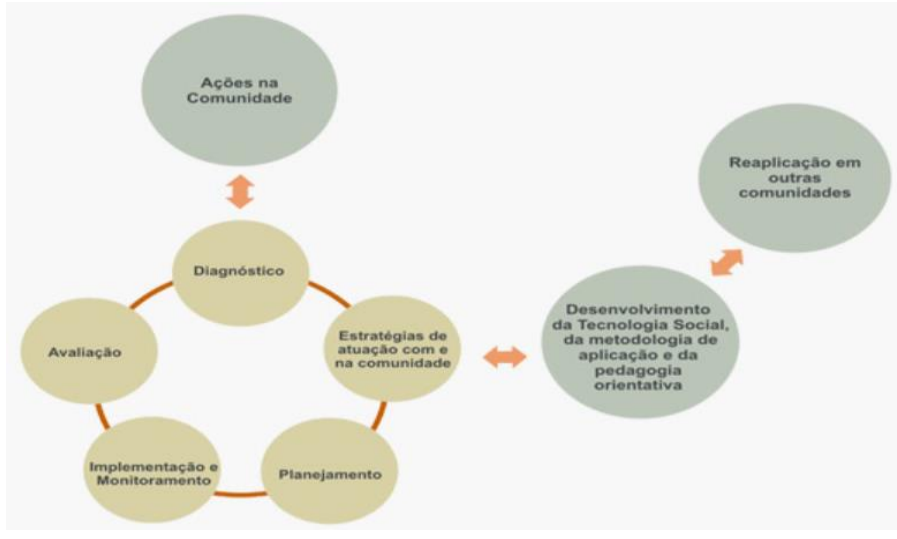

Figura 1 - Etapas no processo de inovação grassroots

Fonte: Instituto Kairós (http://institutokairos.org.br/tecnologias-sociais) Acesso em 14/07/2019.

\subsubsection{Caso de Inovação Grassroots}


Em 2001, a Fundação Banco do Brasil organizou um prêmio anual para iniciativas de Tecnologia Social. Um banco de dados associado inclui centenas de exemplos de inovação de base, principalmente nas áreas de produção agroecológica, coleta de água e saneamento, educação e energia renovável. Mas apenas alguns desses exemplos foram selecionados para reaplicação e expansão, obtendo-se assim acesso a financiamento e apoio de instituições. (FRESSOLI, et al, 2014).

Um exemplo foi o Programa Um Milhão de Cisternas (P1MC). A cisterna é um coletor de água de chuva de camada simples projetado para ser construído pela comunidade local. $\mathrm{O}$ P1MC, como se tornou amplamente conhecido, tinha como objetivo construir um grande número de cisternas de água em uma grande região semi-árida no Nordeste do Brasil, com uma população de cerca de 25 milhões. A região é caracterizada por baixa pluviosidade e escassas fontes de água subterrânea. As cisternas de escala familiar capturaram e armazenaram chuvas sazonais suficientes para necessidades pessoais e produtivas (por exemplo, agricultura) durante a estação da seca.

O programa de cisternas foi originalmente concebido pela Associação Semi-árida, uma rede de mais de 700 instituições, movimentos sociais, ONGs e grupos de agricultores, que mais tarde se tornou um ator importante da STN. O Ministério do Meio Ambiente do Brasil também estava envolvido inicialmente, embora o programa tenha sido posteriormente adotado pelo Ministério do Desenvolvimento Social. Se propôs a construção de contêineres simples de cimento que coletam a água da chuva do telhado, com capacidade para cerca de 16.000 litros, o suficiente para sustentar as necessidades da família na temporada de seca da região (FRESSOLI, et al, 2014).

\subsection{INOVAÇÃO NATIVA EM ECONOMIAS EMERGENTES}

Um mercado emergente pode desenvolver tecnologias próprias a partir do conhecimento gerado localmente. No Brasil, a instituição de pesquisa agropecuária EMBRAPA foi criada na década de 70 visando desenvolver um modelo de agricultura genuinamente brasileiro no cerrado brasileiro, considerado até então improdutivo (Araujo et. al., 2011). Em 2011 empregava 8,5 mil pessoas, sendo 2,2 mil pesquisadores trabalhando essencialmente na elaboração de produtos, processos e serviços agropecuários.

Inovação nativa tem como principal característica a transferência de tecnologia entre países mais desenvolvidos para países menos desenvolvidos, apresentando efeitos para empreendedores locais da base da pirâmide (BREM, WOLFRAM, 2014).

A atuação da empresa no exterior faz parte de uma estratégia do governo para ajudar outros países. Desde os anos 2000 a empresa tem realizado esforços para revolucionar o potencial produtivo da savana africana, que possui características semelhantes às do cerrado brasileiro. Em 2006 foi criado um escritório na África, permitindo a capacitação de profissionais africanos e transferência de conhecimento e tecnologia possibilitando soluções para reduzir a fome e desnutrição no continente. (FAO, 2015).

A África Brazil é uma plataforma de cooperação criada para promover pesquisa e inovação agropecuária na África, com financiamento interno e externo desenvolve programas agropecuários, como exemplo, um projeto com o objetivo de introduzir um sistema de produção de algodão por meio de variedades no manejo do plantio direto e no controle integrado de pragas. Com a transferência de tecnologia do Brasil para a África foi possível realizar a 
inovação nativa com o uso de recursos locais para o desenvolvimento de novas tecnologias (FAO, 2015).

\subsection{INOVAÇÃO JUGAAD}

O cenário do mercado atual tem exigido das empresas um ritmo contínuo de inovação para manter, melhorar ou conseguir uma colocação no mercado em que atuam. Inovar na era de revolução tecnológica é questão de sobrevivência para as pequenas e médias empresas. No entanto, as pequenas e médias empresas enfrentam uma série de obstáculos na hora de inovar, Caron (2004).

A escassez de recursos gera dúvidas quanto à satisfação da necessidade básica do ser humano, à superpopulação, ao crescimento da pobreza e da desigualdade social. Essas questões têm contribuído para que empresas e indivíduos de países emergentes encontrem soluções rápidas e baratas, que não dependam de produtos altamente tecnológicos e que sejam alcançáveis pelas pessoas da região, Caron (2004).

De acordo com um levantamento documental na publicação Guia do Investidor (2019), os países emergentes vêm investindo para aumentar sua capacidade produtiva, surgem com algumas características que vem afastando-os de suas economias tradicionais, dependentes da agricultura e da exportação de matéria-prima na forma de commodities.

Uma dessas características consiste na renda per capita abaixo da média, o que os estimulam a perseguir um crescimento mais veloz. Em 2017, aponta o Guia, a maioria dos países desenvolvidos, como Estados Unidos, Alemanha, Reino Unido e Japão, tiveram um crescimento econômico inferior a 3\%. O crescimento no Egito, Polônia e Marrocos foi de aproximadamente $4 \%$. China, Turquia e Índia tiveram um crescimento de $7 \%$ em sua economia.

Oscilações cambiais fortes, também caracterizam os emergentes deixando-os mais vulneráveis em razão das oscilações das commodities, como o petróleo e alimentos. Destaca também o documento, a baixa disponibilidade de capital de investimentos, agravada por um mercado de capitais menos experiente, situação cuja superação é imprescindível para suportar o crescimento.

O Guia do Investidor (2019) menciona ainda, o relatório Índice de Mercados Emergentes do Morgan Stanley Capital International, responsável por monitorar a capitalização de mercado de todas as empresas listadas no mercado de ações. Esse relatório aponta vinte e três países classificados como emergentes: Brasil, Hungria, China, Colômbia, República Tcheca, Egito, Grécia, Chile, Índia, Indonésia, Taiwan, Malásia, México, Marrocos, Catar, Peru, Filipinas, Polônia, Turquia, África do Sul, Coréia do Sul, Coreia, Tailândia, Rússia e Emirados Árabes Unidos.

A publicação cita a Índia e a China como destaque no mercado emergente. Juntas, abrigam $40 \%$ dos recursos humanos e da população do mundo. A produção combinada desses países em 2017 (US\$ 32,6 trilhões) foi superior à produção da União Europeia (US\$ 20,9 trilhões) ou dos Estados Unidos (US\$19,4 trilhões).

As empresas se envolvem com diferentes tipos de inovação. A inovação incremental consiste num aprimoramento das tecnologias já existentes, levando a melhoria de suas qualidades e funcionalidades. Maçães (2007). A inovação radical, também citada pelo autor, consiste na criação de produtos e serviços novos. 
A emergência dos países em desenvolvimento repercutiu no fenômeno da inovação, fazendo surgir novos formatos, como a denominada inovação Jugaad, expressão de origem indiana, para definir a inovação por improviso, Bernardes et al (2018). Trata-se, segundo os autores, de uma inovação frugal, aquela que procura reduzir a utilização de recursos para produzir um produto ou serviço. O espírito Jugaad dispensa grandes estruturas de Pesquisas \& Desenvolvimento e suporte de alta tecnologia, presentes nas economias mais avançadas.

A inovação por improviso, continua pensando o autor, é flexível e não se limita apenas a sua região ou país de origem. O improviso supera percalços que porventura surgem, como catástrofes naturais, falta de energia elétrica e de capital. Inventores e pequenos empreendedores de países emergentes enxergam no improviso uma oportunidade de superar esses tipos de problemas.

\subsection{INOVAÇÃO FRUGAL}

A área da Inovação tem manifestado crescente atenção a estratégia emergente de inovação chamada de inovação frugal (Tiwari, Herstatt; 2012; Zeschky et al; 2011; Bhatti 2012). O significado da palavra frugal, conforme o dicionário Oxford (2019), caracteriza-se como um adjetivo relativo ao caráter econômico de ser comedido na utilização de recursos, de evitar desperdícios.

Ao incorporar-se no conceito de inovação, o termo frugal indica o processo de criação de produtos e serviços eficientes e eficazes, com qualidade para um público consumidor global preocupado em relação aos seus gastos pessoais e com consciência ambiental e social. Condições essas, onde as empresas atuam em ambientes de recursos escassos e por isso devem alcançar mais e melhor com menos recursos (RADJOU, PRABHU, 2015).

Em suma, a Inovação Frugal consiste numa estratégia de inovação emergente com base no processo de redução de custos e recursos não essenciais de bens duráveis, destinados ao fornecimento de populações de países de baixa renda, uma vez que este público não possui recursos financeiros adequados para o consumo de produtos e serviços desenvolvidos e comercializados nos mercados desenvolvidos, de acordo com Prahalad (2010).

A produção, a gestão e o desenvolvimento de produtos e serviços de qualidade com economia e restrição de recursos para consumidores na base da pirâmide caracteriza a Inovação Frugal (BREM, WOLFRAM, 2014); o conceito também é compreendido com uma reposta de ecossistemas empreendedores com fortes limitações de recursos para criar produtos com vantagens elevadas de custo em comparação com as soluções padrão (ZESCHKY et al., 2011).

No Brasil, o tanquinho de lavar roupas é um exemplo conhecido. Desenvolvido como uma simplificação da máquina de lavar padrão, com reduções de algumas funções como enxague e centrifugação que foram determinantes na redução de custos e de seu preço final ao consumidor alcançando um público na base da pirâmide.

Atualmente o tanquinho possui diversos tamanhos e funcionalidades dependendo das necessidades de cada consumidora o que traz facilidades ao consumidor que não possui recursos disponíveis para comprar uma máquina de lavar padrão.

A inovação frugal do tanquinho impulsionou também as empresas de produtos de limpeza que criaram produtos de ação mais prolongada como o "OMO Tanquinho" ao analisar o consumo de água utilizada para suas lavagens.

\subsection{INOVAÇÃO EM CUSTO}


O estudo realizado permitiu constatar o aumento o número de empresas que seguem a filosofia low cost. A estratégia de redução de custos é cada vez mais utilizada por organizações de diversificados negócios e está diretamente ligada à classe média ou a classes com rendimentos mais baixos.

Ao perceberem que um volume significativo de consumidores pertencem a essas classes, as empresas passaram a focar suas necessidades, Wolf (2004). O crescimento das empresas orientadas por esse conceito deve-se essencialmente à deterioração da classe média dos Estados Unidos e da Europa (PRAHALAD, 2010) na última década, que busca a manutenção do consumo por um preço mais reduzido. Como reflexo disso as empresas vislumbram um crescimento por conta desses novos consumidores, incluindo aí mercados de países como Brasil, China, Índia, Turquia e Rússia. Gaggi e Narduzzi (2006).

Algumas características são marcantes na modalidade de inovação em custo, como: a inclusão de alta tecnologia a custo baixo; padronização de partes de um produto para posterior customização; e produção em escala para mercados concentrados (WILLIAMSON; ZENG, 2007).

\subsubsection{O caso WaveTech de inovação em custo}

Mantida pela Fundação CERTI (Centros de Referência em Tecnologias Inovadoras), criada em 1986, com sede na cidade de Florianópolis, o Centro Empresarial para Laboração de Tecnologias Avançadas (CELTA) é uma incubadora, que surgiu para participar do desenvolvimento catarinense. Atua incentivando o setor econômico a investir nos talentos egressos da Universidade Federal de Santa Catarina (UFSC). Tem como missão a prestação de suporte a Empreendimentos de Base Tecnológica - EBTs e, estimulando a sua criação, desenvolvimento, consolidação e interação com o meio empresarial e científico.

Dentre es empreendimentos destaca-se a WaveTech, empresa criada em 2012, que recebeu, em 2016, autorização da Anvisa (Agência Nacional de Vigilância Sanitária) para a comercialização de um aparelho auditivo criado com auxílio do programa Tecnova, operado pela Fapesc (Fundação de Amparo à Pesquisa e Inovação do Estado de Santa Catarina) e Finep (Financiadora de Estudos e Projetos).

Este aparelho é novidade uma vez que não faz uso de fios na integração de suas partes e tem no seu software a compatibilidade com a plataforma utilizada pelos demais produtos da linha.

Outro ponto favorável é que na América Latina existem somente montadoras e não desenvolvedores de aparelhos auditivos e ainda que existam por volta de 30 marcas, são agrupadas em 4 grandes empresas, fazendo com que os valores tenham uma variação entre $\mathrm{R} \$$ $3.500,00$ e R $\$ 28.000,00$, o que impede as classes C, D e E, de ter acesso a esse atendimento (FAPESC).

\subsection{INOVAÇÃO SHANZHAI}

A palavra Shanzhai é conhecida na China por designar produtos copiados de marcas que alcançaram notoriedade. Trata-se de uma variante mais simples e de custo reduzido de um produto superior destinado ao atendimento de consumidores locais que não reúne condições para adquirir o produto original. Essa estratégia de inovação adotada em países emergentes caracteriza a inovação Shanzhai, BENNETT (2010). 
Trata-se de um tipo de inovação que permite às empresas seguidoras competir com as lideranças de mercado e sinaliza oportunidades para a intervenção de políticas públicas em mercados de grandes quantidades de consumidores com capacidade de consumo restrita, como ocorre nos países emergentes. Uma boa alternativa para a inovação não se resume a copiar ou imitar, mas inovar a partir da imitação. SHENKAR (2010).

A adoção desse tipo de inovação segue um curso progressivo de três etapas. A primeira - "copiar e colar"- diz respeito à identificação de aspectos do produto a serem reproduzidos a baixo custo e que possa ser destinado inclusive ao mercado externo. A segunda, "camadas e modularização"- refere-se ao início da fase de aperfeiçoamentos e adaptação para que possam ser intercambiáveis e tenham componentes de reposição. A terceira, inovação, o momento em que a empresa já consolidada começa a gerar inovações que possam ser agregadas a seus produtos. Nesse caso, a inovação ocorre por força de um aprimoramento gradual. Na China, responsável por extensa pauta de exportação, a inovação Shanzhai tem papel importante no considerável crescimento do País (CHA, 2012).

No Brasil, envolvida em tabus, trata-se de inovação associada a produtos genéricos, de imitação barata, falsificados ou fruto de "pirataria", ofertados intensivamente no mercado doméstico por loja populares e camelôs.

\subsection{INOVAÇÃO REVERSA}

A Inovação Reversa via de regra é desenvolvida em países emergentes como Brasil, China, Índia ou Rússia, a partir da transferência das áreas de pesquisa e desenvolvimento de multinacionais cuja preocupação passa de fornecer um produto global sem adaptações para um produto adaptado e melhorado para as condições locais, criando assim um diferencial estratégico na conquista e manutenção deste mercado (GOVINDARAJAM, TRIMBLE; 2012). Representa a inovação direcionada a países em desenvolvimento por multinacionais estrangeiras, o que implica afirmar que o país em desenvolvimento é que se encontra no centro da inovação (GOVINDARAJAN, RAMAMURTI, 2011).

Neste sentido ao invés das inovações serem efetuadas em mercados desenvolvidos e transferidas para mercados emergentes, elas foram geradas em mercados emergentes para então serem transferidas para os mercados desenvolvidos (BERNARDES et al, 2018). Deve-se ressaltar a mudança de hábito que leva muitos clientes dos mercados desenvolvidos a serem atraídos pelos custos mais baixos com inovações boas e frugais desenvolvidas para os mercados emergentes. É crescente o número de empresas que estão implantando suas inovações com recursos limitados nos mercados ocidentais com a finalidade de atrair esta clientela ou para preencher as lacunas não atendidas em grandes mercados desenvolvidos (ZESCHKY, WINTERHALTER, GASSMANN; 2014).

\section{DISCUSSÃO SOBRE A INOVAÇÃO NO BRASIL}

Como foi comentado, no que diz respeito à inovação, o quadro brasileiro apresenta desvantagens em ralação a vários outros países emergentes, em razão da pouca disponibilidade relativa de recursos, dentre outros motivos. Na esfera da Pequena e Microempresa (MPE) a atividade depende de um quadro institucional complexo para suportar o processo de inovação (Lisowska; Stanislawski, 2015). Inovações originadas no processo decisório da MPE, para 
Woschke e Haase (2016) é fundamental para o desenvolvimento de novos produtos e mercados e para cultivar uma cultura favorável à inovação.

De fato, o Brasil não se destaca sequer entre os países das América Latina, coloca-se 20 posições abaixo do Chile ( $47^{\circ}$ lugar), levando-se ainda em conta os desafios que a inovação enfrenta no Brasil, sobretudo em razão de excessos burocráticos, pouco investimento na esfera pública e privada, precariedade na qualificação de pessoas. Paradoxalmente, o País tem no seu povo indiscutível aptidão para a criatividade e conseguiu criar alguns pontos avançados e prósperos de inovação.

Inovação Grassroots no Brasil é caracterizada principalmente pela atuação de atores da sociedade civil. Empreendedores sociais apoiados em ONGs, cooperativas e outras entidades do gênero, buscam recursos originários no apelo altruísta, nas agências intergovernamentais (ligados à $\mathrm{ONU}$ ) e nas políticas públicas para o atendimento de necessidades socioambientais. Opera com base no conhecimento local nativo e na experimentação. De modo emblemático a inovação Grassroots atua nas áreas de saneamento e energia renovável em pequena escala. (SMITH, FRESSOLI, THOMAS, 2014).

Em que pese a acanhada posição do Brasil no ranque global de inovações (Agência de Notícia-CNI (2017) ${ }^{1}$, o País apresenta, pontualmente, algumas iniciativas que se destacam no campo da inovação. A exemplo disso, a EMBRAPA (Empresa Brasileira de Pesquisa Agropecuária) vem trabalhando no âmbito de uma política governamental voltada para países africanos, para transformar, com a denominada inovação nativa, a capacidade produtiva da savana africana (FAO, 2015).

A África Brazil é uma inovação nativa que consiste numa plataforma de cooperação criada para transferir tecnologia da inovação agropecuária do Brasil para a África. Foi possível realizar a inovação nativa com o uso de recursos locais para o desenvolvimento de novas tecnologias (FAO, 2015).

O Brasil revela traços potenciais para a inovação Jugaad. O famoso espírito cultural do "jeitinho brasileiro", se aproveitado positivamente, pode ser traduzido na versatilidade do cidadão brasileiro para o improviso. Esse perfil facilita o atendimento de seis princípios indispensáveis para a inovação Jugaad: fazer mais com menos; ser flexível; oportunizar adversidades; simplificar soluções; valer-se da intuição e ampliar o acesso dos segmentos menos favorecidos (BERNARDES et al, 2018).

A inovação Jugaad, como foi visto, beneficia uma região específica, estimulando sua economia. Embora típica do comportamento criativo do brasileiro, do ponto de vista comercial, são incipientes as iniciativas brasileiras nessa modalidade de inovação. A propósito, como já foi citado, o Brasil está distante no ranking de países inovadores. É citada na pesquisa o índice global de inovação (IGI) de 2018, mostrando uma tímida evolução em relação ao ano anterior, apontando que dos 126 países avaliados, o Brasil ocupa a $64^{\circ}$ no ranking.

1 Brasil ocupa a $69^{a}$ posição no Índice Global de Inovação em ranking com 127 nações. Série de reportagens do especial O Brasil que inova. Agência de Notícia, Confederação Nacional da Indústria-CNI. Editorial: Inovação e Tecnologia. Inovação no Brasil vai na contramão do mundo, 2017. 
Um outro exemplo de inovação emergente recorrente na literatura, é a inovação frugal do "tanquinho" de lavar roupas, que consiste numa opção simplificada da máquina de lavar tradicional destinado a um público de renda mais baixa.

Em relação à Inovação Reversa, no Brasil ocorreu a experiência da tecnologia de combustíveis FLEX, desenvolvida pelas montadoras multinacionais, no entanto a estratégia de inovação reversa foi pouco exportada para outros países.

A inovação Shanzhai no Brasil é envolvida em tabus, está associada a produtos genéricos, de imitação barata, falsificados ou fruto de "pirataria", ofertados no mercado doméstico por lojas populares e camelôs. Portanto, com ampla ocorrência no País e intensiva oferta no mercado doméstico, mas sem impacto na exportação.

\subsection{Relação entre inovação emergente e inovação no Brasil}

Sintonizado com o objetivo do estudo, o quadro $\mathrm{n}^{0} 1$ apresenta um resumo dos pontos levantados na discussão, reproduzindo a relação entre as diversas formas de inovação que ocorrem nos mercados emergentes e as ocorrências registradas no Brasil.

Quadro 1. Relação entre tipos de inovação nos mercados emergentes e sua ocorrência no Brasil.

\begin{tabular}{|c|c|c|}
\hline \multicolumn{3}{|c|}{ Estratégias de inovação em mercados emergentes - novos formatos } \\
\hline Estratégias & Mercados Emergentes & Brasil \\
\hline Reversa & $\begin{array}{l}\text { Desenvolvida por multinacionais em } \\
\text { mercados emergentes e destinada aos } \\
\text { mercados desenvolvidos }\end{array}$ & $\begin{array}{l}\text { Ocorrência pontual sem impacto } \\
\text { significativo na pauta de exportação }\end{array}$ \\
\hline Frugal & Custo reduzido, mais acessível & Ocorrência moderada \\
\hline Jugaad & Improviso com custo baixo & $\begin{array}{l}\text { Mais frequente, mas sem impacto } \\
\text { mercadológico significativo }\end{array}$ \\
\hline Custo & $\begin{array}{l}\text { Oferta alternativa a custo menores de } \\
\text { produtos com apelo tecnológico }\end{array}$ & $\begin{array}{l}\text { Casos pontuais bem sucedidos, mas } \\
\text { sem impactos significativos em termos } \\
\text { comerciais }\end{array}$ \\
\hline Shanzhai & Cópia e aprimoramento & $\begin{array}{l}\text { Visto no Brasil como "pirataria". } \\
\text { Ocorrência ampla no mercado interno, } \\
\text { mas sem impacto na exportação }\end{array}$ \\
\hline Grassroots & $\begin{array}{l}\text { Rede de ativismo que busca soluções } \\
\text { sustentáveis }\end{array}$ & Ocorrência moderada \\
\hline Nativa & $\begin{array}{l}\text { Transferência de tecnologia de países mais } \\
\text { desenvolvidos para países menos } \\
\text { desenvolvidos }\end{array}$ & Ocorrência moderada \\
\hline
\end{tabular}

Fonte: elaboração dos autores.

Embora sem grande alcance em termos de mercado externo, variados casos de sucesso levantados no estudo demostram que existe um Brasil inovador. No entanto, a inovação no País tem sua ocorrência marcada por certa hesitação quanto à escolha estratégica adotada. Como se pode notar, em relação a tipologia de inovação dos mercados emergentes, o Brasil pendula entre 
uma atuação apenas moderada e uma atuação mais intensa, mas sem ganhos de escala e sem alcance significativo no mercado externo.

De fato, essa hesitação fica patente quando se leva em conta que as políticas públicas não são explícitas quanto a opção a adotar. Seguir uma rota dependente de alta tecnologia e pesquisa, seguir um roteiro considerando as adversidades próprias dos mercados emergentes ou, ainda, conciliar as duas opções por não serem excludentes.

A reflexão sobre esses aspectos pode ser útil na potencialização da inovação no Brasil e sinaliza os ganhos que poderiam ser obtidos com essa visão.

\section{CONSIDERAÇÕES FINAIS}

As nações desenvolvidas fazem forte investimento em inovação por compreenderem que esse é o caminho para manterem suas posições. Enquanto isso, os países emergentes enfrentam burocracia exacerbada, contingenciamento de recursos e gaps de conhecimento, criando condições hostis para a inovação, esta seria uma primeira conclusão corroborada numa das constatações do painel realizado no $8^{\circ}$. Congresso Brasileiro de Inovação da Indústria, publicado em editorial da Agência de Notícia da Confederação Nacional da Indústria, em 2017.

A posição do Brasil do no ranque de inovações não é compatível com o porte de sua economia (66 lugar, IGI-GII-2018). Em termos de Ecossistema de Inovação e tecnologia o Brasil tem muito que percorrer. Não basta aprender com os ecossistemas de Massachusetts, Califórnia ou Israel buscando tecnologia de ponta em várias áreas e criando ilhas pontuais de tecnologia e inovação, é preciso incorporar de modo decidido as iniciativas de inovação impelidas pelas adversidades típicas dos países emergentes. Seria outra conclusão implícita na questão examinada no estudo, indicada em painel do Congresso Brasileiro de Inovação da Indústria, realizado em 2017.

Grandes centros de P\&D privados e governamentais, desbravadores do avanço na ciência e tecnologia, cedem lugar aos modelos abertos e de colaboração, possibilitando mudanças importantes na inovação. Embora as políticas governamentais brasileiras nem sempre são ajustadas para conduzir ou fomentar esse processo, como relata Scheinkman (2018), pode-se concluir que a movimentação dos mercados emergentes, incluindo o Brasil, caminha na direção dos sistemas abertos de colaboração.

De fato, presencia-se no Brasil, segundo o último autor mencionado, o chamado "grassroots movement" (movimento social que busca dotar grupos locais de poder) em várias localidades, como Santa Catarina, Minas Gerais, Recife, São Paulo, Campinas e São José dos Campos. Com muito interesse no setor de tecnologia e inovação, muita curiosidade e com talento inovador, estes grupos têm gerado o aumento do número de empresas e buscado desafios audaciosos.

Uma outra consideração sobre a mudança para sistemas abertos, diz respeito à ênfase recaída sobre o método de inovação. A multiplicidade de maneiras de fazer inovação vem melhorando a mentalidade e compreensão do processo, despertando interesse crescente de agentes públicos e privados envolvidos no problema.

$\mathrm{O}$ estudo permite salientar algumas dificuldades, descritas de forma recorrente na literatura, que tem forte repercussão negativa na inovação, de onde se destacam o rito burocrático, uma vez que a inovação depende de um movimento ativo e veloz e a qualificação, 
problema de solução complexa por depender de pessoas e imprescindível quando se pensa em inovação em grande escala.

O estudo nos permite arriscar que o Brasil enfrenta o dilema da hesitação. As políticas públicas são desprovidas de clareza quanto ao caminho a seguir. A escolha entre a inovação baseada no conjunto alta tecnologia e investimento $\mathrm{P} \& \mathrm{D}$ e baseada nas condições adversas naturais dos países emergentes não são mutuamente excludentes. Essa visão pode ser útil na potencialização da inovação no País.

O concerto entre universidades, empresas e unidades de pesquisa, tem sido apontado como uma importante solução para a inovação no Brasil, que tem muito que caminhar nesse sentido. Parece senso comum o entendimento de que a atuação conjunta dessas instituições contribui decisivamente para a inovação, seria mais uma constatação observada no estudo.

Espera-se com essas reflexões, sobre as estratégias de inovação adotadas nos mercados emergentes, vislumbrar possibilidades que podem emergir com essas novas rotas de inovação para que se possa reexaminar o caminho da inovação para o Brasil.

As variadas perspectivas que possam ser adotadas para observar e analisar os problemas que se pode estabelecer a partir do tema inovação, recomendam estudos futuros mais aprofundados em suas diversificadas vertentes, de modo a permitir um olhar mais apurado sobre a complexa tarefa de examinar o fenômeno da inovação no Brasil.

\section{Referencias}

AGÊNCIA DE NOTÍCIA CNI. Editorial: Inovação E Tecnologia. Inovação no Brasil vai na contramão do mundo, 2017.

ANGOT, J.; PLÉ, L. Serving poor people in rich countries: the bottom-of-the-pyramid business model solution. Journal of Business Strategy, v.36, n.2, p.3-15, 2015.

ANSOFF, H. I. Estratégia Corporativa: Uma Abordagem Analítica da Política Empresarial para Crescimento e Expansão. New York: McGraw-Hill, 1965.

ARAUJO, U. P. et al. «Consubstanciação da imagem da Embrapa no campo científico" Revista de Administração Pública, Rio de Janeiro, 45 (3), jun, 2011, pp. 775-812.

BARKI, E.; PARENTE, J. Consumer behaviour of the base of the pyramid market in Brazil. Greener Management International, v.56, n.56, p. 11-23, 2010.

BARNEY, J. B., HESTERLY, W. S. Administração Estratégica e Vantagem Competitiva. Pearson Prentice Hall Editora, 2008.

BENNETT, D. The Imitation Economy. Boston Globe, 2010.

BERNARDES, R. C.; BORINI, F. M. (Org.); ROSSETO, D. (Org.); PEREIRA, R. (Org.). Inovação em Mercados Emergentes. 1. ed. São Paulo: Editora Senac, 2018. v. 1. 1p.

BESSANT, J. TIDD, J. Inovação e empreendedorismo. Porto Alegre: Bookman, 2009.

BHATTI, Y. A. What is frugal, what is innovation? Towards a theory of frugal innovation. Towards a Theory of Frugal Innovation (February 1, 2012), 2012. 
BREM, A., WOLFRAM, P. Research and development from the bottom up: introduction of terminologies for new product development in emerging markets. Journal of Innovation and Entrepreneurship, v. 3, n. 1, p. 9, 2014.

BULMER, M. Sociological research methods. London: Macmillan, 1977.

CARON, A. Inovação tecnológica em pequenas e médias empresas. Revista FAE BUSINESS, número 8, maio/2004.

CHA, V. Shanzhai and Growth Hacking. Slide, 2012.

CHANDLER Jr.A.; DAEMS, H. Hierarquias de Gestão: perspectivas comparativas sobre o moderno desenvolvimento da empresa industrial. Oieiras: Celta Editora, 1994.

CHRISTENSEN, C. M. O dilema da inovação: quando as novas tecnologias levam as empresas ao fracasso. São Paulo: Makron Books, 2012.

CRESWELL, J. W. Projeto de pesquisa: métodos qualitativo, quantitativo e misto. 3. ed. Porto Alegre: Artmed, 2010. 2005.

DRUCKER, P. F. Inovação e Espírito Empreendedor. São Paulo: Entrepreneurship,

EISENHARDT, K.M. Building theories from case study research. Academy of Management Review, Vol. 14, No. 4, pp. 532-550, 1989.

FAO. Número de pessoas que passam fome está abaixo de 800 milhões: o próximo objetivo é a erradicação. 27/05/2015. Disponível em http:// www.fao.org/brasil/noticias/detailevents/en/c/292931. Acesso em 14/07/2019.

FIGUEIREDO, P. N. Gestão da Inovação: conceitos, métricas e experiências de empresas no Brasil. Rio de Janeiro: LTC, 2011.

FLICK, U. Métodos de Pesquisa: introdução à pesquisa qualitativa. $3^{\mathrm{a}}$ Ed. Porto Alegre: Artmed, 2009.

FRESSOLI, M., AROUND, E., ABROL, D, SMITH, A., ELY, A., DIAS, F. When grassroots innovation movements encounter mainstream institutions: implications for models of inclusive innovation, Innovation and Development, 4:2, 277-292, 2014. DOI: 10.1080/2157930X.2014.921354

Frugal.(2019). Em OxfordDictionaries.com. Recuperado de https://en.oxforddictionaries.com/definition/frugal

GAGGI, M, e NARDUZZI, E. Low Cost: O fim da classe média, Teorema, 2006

GHESALAGA, R.; MARSHALL, P. Purchasing power at the bottom of the pyramid: differences across geographic regions and income tiers. Journal of Consumer Marketing, v.25, n.7, p.413-418, 2008.

GIL, A. C. Como elaborar projetos de pesquisa. 5. ed. São Paulo: Atlas, 2010.

GOVINDARAJAN, V., \& RAMAMURTI, R. Reverse innovation, emerging markets, and global strategy. Global Strategy Journal, 1(3- 4), 191-205, 2011. 
GOVINDARAJAN, V., \& TRIMBLE, C. Reverse innovation: a global growth strategy that could pre-empt disruption at home. Strategy \& Leadership, 40(5), 5-11, 2012.

GRIZENDI, E. Manual de orientações gerais sobre inovação. [Brasília, DF]: Ministério das Relações Exteriores. Departamento de Promoção Comercial e Investimentos. Divisão de Programas de Promoção Comercial. 2011. Acesso em 10 de junho 2019.

GUIA DO INVESTIDOR O que são mercados emergentes? O Brasil faz parte?; disponível em https://guiadoinvestidor.com.br/o-que-sao-mercados-emergentes-o-brasil-fazparte/, publicado 12/02/2019; acessado em 03/07/2019.

HITT, M. A.; IRELAND, R. D.; HOSKISSON, R. E. Administração estratégica: competitividade e globalização. 2. ed. São Paulo: Thomson Learning, 2008.

Global Innovation Index (GII) publicação da Business School Insead, da Cornell University, e da World Intellectual Property Organization, 2018.

INSTITUTO KAIRÓS. Disponível em http://institutokairos.org.br/tecnologias-sociais. Acesso em 14/07/2019.

KHALID, R. U. et al. Putting sustainable supply chain management into base of the pyramid research. Supply Chain Management: An International Journal, v.20, n.6, p.681-696, 2015 .

KÖCHE, J. C. Fundamentos de metodologia científica. 27. ed. Petrópolis, RJ: Vozes, 2010 .

LISOWSKA, R.; STANISLAWSKI, R. The Cooperation of Small and Medium-sized Enterprises with Business institutions in the context of Open Innovation. Procedia Economics and Finance. V. 23, p. 1273, 2015.

MAÇÃES M. A. R. Empreendedorismo, Inovação e Mudança Organizacional; Editora Atual. Lisboa: 2007.

OCDE-Manual de Oslo.Diretrizes para coleta e interpretação de dados sobre inovação. $3^{\mathrm{a}}$. ed. FINEP - Eurostat, 2005. http://download.finep.gov.br/dcom/brasil inovador/ arquivos/manual de oslo/prefacio.html Acesso em: 17 jun. 2019.

MINTZBERG, H. O Processo da Estratégia. Porto Alegre: Bookman, 2002.

PARENTE, J. O Varejo de Alimentos para consumidores de Baixa Renda no Brasil. FGV-EAESP/GV Pesquisa. São Paulo, Relatório n. 16, 2008.

MONTEIRO, M., ROSSETO, D.E., Inovação em Mercados Emergentes / organização de Roberto Bernardes, Felipe Mendes Borini, Dennys Eduardo Rossetto e Rafael Moraes Pereira - São Paulo, Editora Senac São Paulo, 2018, pp. 301-309.

PORTER, MICHAEL E. Vantagem Competitiva: criando e sustentando um desempenho superior. Rio de Janeiro: Campus, 1989. 2005.

PRAHALAD, C. K.; HAMEL, G. Competindo pelo futuro. Rio de Janeiro: Campus. 
PRAHALAD, C. K. A Riqueza na Base da Pirâmide: Como Erradicar a Pobreza com o Lucro. Ed. Rer. atual. - Porto Alegre: Bookman, 2010.

QUINN, J. B. Empresas Muito Mais Inteligentes. São Paulo: Makron Books. 1996.

RADJOU, N., PRABHU, J. Frugal Innovation: How to do more with less. The Economist Books, 2015.

REINERT, E.; REINERT, S. Innovation systems of the past: modern nation-states in a historical perspective. The role of innovations and of systemic effects in economic thought and policy. 2003. Acesso: http://www.ie.ufrj.br/globelics.

ROCHA, A.R.; ROCHA, Â. D. Consumidores da base da pirâmide e as restrições ao laser. Revista Pensamento Contemporâneo de Administração, v.6, n.2, p.1-13, 2012.

RTS - REDE DE TECNOLOGIA SOCIAL, 2015. Disponível em http://www.rts.org.br. Acesso em 08/09/2016.

SACHS, J. The end of poverty: Economic possibilities for our time. European Journal of Dental Education, v.12, n.1, p.17-21, 2008.

SANCHES, C.M.; SCHMID, A.S. Base of the pyramid success: a relational view. South Asian Journal of Global Business Research, v.2, p. 59, 2013.

SARKAR, S. O empreendedor inovador: faça diferente e conquiste seu espaço no mercado. Rio de Janeiro: Elsevier, 2008.

SCHEINKMAN, R. Ecossistema brasileiro de inovação necessita de conexão com hubs de inovação global. IT Forum, 2018.

SCHUMPETER, J. A. A Teoria do Desenvolvimento Econômico: uma investigação sobre lucros, capital, crédito, juro e o ciclo econômico. Tradução de Maria Silvia Passos. São Paulo: Abril Cultural, 1997.

SEYFANG, G., SMITH, A., 2007. Grassroots innovations for sustainable development: towards a new research and policy agenda. Environmental Politics 16, 584-603, 2007.

SHENKAR, O. Copycats: How Smart Companies Use Imitation to Gain a Strategic Edge. Boston: Havard Business Press, 2010.

SMITH, A., FRESSOLI, M.; THOMAS, H. Grassroots innovation movements: challenges and contributions. Journal of Cleaner Production, v. 63, p. 114-124, 2014.

TIDD, J., BESSANT, J., PAVITT, K. Gestão da inovação. 3. ed. Porto Alegre: Bookman, 2008.

TIWARI, R., HERSTATT, C. India-a lead market for frugal innovations? Extending the lead market theory to emerging economies. TIM/TUHH Working Paper, n. 67, 2012. 2010 .

YIN, R. K. Estudo de caso: planejamento e métodos. 4. ed. Porto Alegre: Bookman,

VAN DE VEN, A. Central problems in the management of innovation. Management Science, v. 32, n. 5, p. 590- 607, 1986. 
WILLIAMSON, P. J. e ZENG, M. Dragons at Your Door: How Chinese Cost Innovation is Disrupting Global Competition. Boston: Havard Business School Press, 2007. 2004.

WOLF, M., Why Globalization Works, Yale University Press, New Haven- Londres,

WOOLDRIDGE, A. Grande Disrupção - o desafio dos mercados emergentes em inovação e fabricação. The Economist (Economist Books), 2017.

WOSCHKE, T.; HAASE, H. Enhancing new product development capabilities of small and medium-sized enterprises through managerial innovations. Journal of High Technology Management Research, v. 27, n.1, p. 53, 2016.

ZESCHKY, M., WIDENMAYER, B., GASSMANN, O. Frugal innovation in emerging markets. Research-Technology Management, v. 54, n. 4, p. 38-45, 2011.

ZESCHKY, M. B., WINTERHALTER, S., \& GASSMANN, O. From cost to frugal and reverse innovation: Mapping the field and implications for global competitiveness. ResearchTechnology Management, 57(4), 20-27, 2014. 